\title{
Ganho em peso, características de carcaça e carne de ovelhas terminadas em pasto com teores diferentes de suplementação
}

\author{
Weight gain, carcass and meat traits of ewes finished on pasture with different levels \\ supplementation
}

\author{
SILVA, Fredson Vieira $\mathrm{e}^{1,2^{*}}$; CARVALHO, Zaqueu Gonçalves ${ }^{1}$; SÁ, Hemilly Cristina \\ Menezes de ${ }^{2}$; OLIVEIRA, Laura Lúcia dos Santos ${ }^{1}$; ALVES, Dorismar David ${ }^{1}$; SILVA, \\ Vandenberg Lira ${ }^{2}$; SOARES, Franklin Delano dos Santos ${ }^{1}$; SANTOS, Carlos César \\ Rodrigues dos 1
}

\begin{abstract}
${ }^{1}$ Universidade Estadual de Montes Claros, Departamento de Zootecnia da, Janaúba, Minas Gerais, Brasil. ${ }^{2}$ Universidade Federal de Minas Gerais, Departamento de Zootecnia, Belo Horizonte, Minas Gerais, Brasil.

*Endereço para correspondência: fredson.silva@unimontes.br
\end{abstract}

\section{RESUMO}

Objetivou-se com este trabalho avaliar o ganho em peso e as características de carcaça e carne de ovelhas de descarte mantidas em pasto de Panicum maximum, cultivar Massai, consumindo diferentes teores de concentrado. $\mathrm{O}$ delineamento foi inteiramente casualizado e as fêmeas foram distribuídas em quatro tratamentos, zero; 0,$7 ; 1,4$ e $2,1 \%$ do seu peso vivo em suplementação concentrada. Ao final de oitenta dias de experimento no campo, as fêmeas foram abatidas. Mediu-se o ganho em peso dos animais e as características das carcaças e das carnes. Os dados foram interpretados após análises de variância e regressão $(\mathrm{P}<0,0500)$. $\mathrm{O}$ ganho em peso máximo foi obtido com a ingestão de $1,49 \%$ de concentrado em função do peso vivo, ponto próximo no qual se obteve melhor conversão alimentar. Contudo, a relação custo benefício foi melhor com a ingestão próxima a $0,62 \%$ de concentrado em função do peso vivo. As carcaças não apresentaram modificações e o ganho em peso corporal foi obtido em gordura nas vísceras. As carnes apresentaram menor $\mathrm{pH}$ final quando as ovelhas consumiram mais concentrado. As perdas durante o cozimento foram menores com a ingestão de $2,0 \%$ do peso vivo em concentrado proteico. As carnes de todos os tratamentos foram consideradas macias, contudo, a sua coloração encontrou-se no limite inferior da faixa normal da espécie.

Palavras-chave: composição corporal, Santa Inês, sistemas de produção

\section{SUMMARY}

This work was carried out in order to evaluate weight gain and carcass and meat traits of culling ewes kept on grass Panicum maximum cultivar Massai, consuming different levels of concentrate. The design was entirely at random and females were distributed into four treatments, zero, $0.7,1.4$ and $2.1 \%$ of its body weight in concentrate supplementation consumed. The females were slaughtered at eighty days of the experiment. We measured the weight gain of animals and carcass and meat traits. The data were interpreted after analysis of variance and regression $(\mathrm{P}<0.0500)$. The maximum weight gain was observed with intake of $1.49 \%$ concentrate as a function of body weight, point closed to which it was obtained the best feed conversion. However, the cost benefit was better with intake of $0.62 \%$ concentrate depending on the body weight. Carcasses did not show changes, and the gain in body weight was obtained in visceral fat. Meat showed lower ultimate $\mathrm{pH}$ and lower losses during cooking when the culling ewes consumed more concentrates. All treatments possessed tender meats, however, its color was found in the bottom limit of the normal range of specie.

Keywords: body composition, production systems, Santa Ines 


\section{INTRODUÇÃO}

Credita-se parte da desarticulação da cadeia produtiva da carne ovina à sazonalidade da produção. Além de animais jovens, a terminação de ovelhas pode ser uma alternativa para suprir uma quota do mercado de carnes in natura e/ou industrializadas. As ovelhas são substituídas por fêmeas mais jovens quando alcançam a idade cronológica de quatro anos, em média. Estes animais serão, invariavelmente, destinados ao abate.

A suplementação na dieta de animais jovens criados em pasto nas condições de clima semiárido, possibilita a obtenção de carcaças mais pesadas, com melhores rendimentos e menor perda de peso durante o resfriamento (DANTAS et al., 2008). Estas características estão relacionadas à maior eficiência de produção.

No entanto, a avalição zootécnica das fêmeas de descarte faz-se necessário, pois após a maturidade os animais diminuem seu desenvolvimento (BUTTERFIELD, 1988) e as suas carnes podem ter pior qualidade sensorial.

Para auxiliar na caracterização dos animais, as mensurações realizadas nas carcaças de ovinos correlacionam-se com os seus tecidos e conformações (MURTA et al., 2009) e podem ser utilizadas na predição do ganho médio diário em peso vivo e rendimento da carcaça (ALVES et al., 2013).

Diante destas considerações, a avaliação de dietas que possam melhorar o desempenho dos animais e a qualidade das carnes pode ser uma alternativa para disponibilizar animais para o abate em melhores condições.

O ganho em peso de animais que recebem suplementação geralmente é superior ao daqueles que estão exclusivamente no pasto, no entanto, os custos deste sistema pode limitar a produção. Portanto, as dietas devem ser avaliadas para que o sistema não se torne oneroso e o plano nutricional seja adequado de acordo com as potencialidades locais.

Este experimento foi realizado para avaliar o ganho em peso, as características da carcaça e da carne de ovelhas de descarte mantidas em pasto submetidas a diferentes estratégias de suplementação.

\section{MATERIAL E MÉTODOS}

O experimento foi realizado em uma fazenda particular situada no município de Januária; rodovia MG135, Km 29. Foram utilizadas vinte e duas ovelhas tipo Santa Inês com aproximadamente quatro anos de idade e peso vivo médio de $42,85 \pm 7,89 \mathrm{~kg}$. Os animais foram distribuídos em quatro tratamentos em delineamento inteiramente casualizado de acordo com a ingestão de concentrado em relação ao peso vivo (zero; 0,$7 ; 1,4 \mathrm{e}$ $2,1 \%$ ). Os tratamentos 0,7 e $1,4 \%$ possuíram seis ovelhas e os outros dois grupos, cinco.

O concentrado foi composto por $90,64 \%$ de panícula de sorgo triturada, $2 \%$ de ureia, $4,36 \%$ de farelo de soja e $3 \%$ de sal mineralizado comercial para ovinos. A forragem utilizada para pastejo foi o Panicum maximum, cultivar Massai, em piquete com quatro hectares, com aproximadamente quinze toneladas de matéria verde/ha/mês disponível, calculada conforme estimativa pelo método do quadrado. $\mathrm{O}$ referido piquete tinha bebedouros e sombreamento natural.

O consumo de matéria seca total foi estimado, utilizando-se o Small Ruminant Nutrition System - SRNS (TEDESCHI et al., 2010; TEDESCHI et 
al., 2008), sendo que o consumo de matéria seca do pasto foi obtido a partir da diferença entre o consumo de matéria seca total Obteve-se a média do peso vivo inicial e final de cada indivíduo para inseri-lo no SRNS. Após, estimouse, por diferença, o consumo da matéria seca da forragem, já que a proporção do concentrado na dieta foi fixa e todos os animais $\mathrm{o}$ ingeriram sem sobras. $\mathrm{O}$ programa permite inserir os dados referentes à categoria animal e a composição dos alimentos. Para a simulação de ingestão da matéria seca total de cada animal, fixou-se os valores de concentrado já conhecidos.

O ensaio teve duração de oitenta e sete dias, sendo sete para adaptação ao manejo alimentar. Imediatamente antes, foi aplicado nas ovelhas anti-helmíntico a base de ivermectina, identificadas e distribuídas aleatoriamente nos tratamentos.

$\mathrm{Na}$ adaptação as ovelhas receberam o equivalente a $25 \%$ do total estabelecido de alimento concentrado nos primeiros três dias e $50 \%$ nos últimos quatro dias. Optou-se por não utilizar $100 \%$ do concentrado durante a adaptação para evitar casos de distúrbios metabólicos, como acidose, por exemplo, já que não se fornecia anteriormente este alimento.

A forrageira descrita foi mantida sob pastejo contínuo das ovelhas, sendo que todos os animais permaneceram o mesmo tempo no piquete, das $8 \mathrm{~h}$ às $12 \mathrm{~h}$ e das $12 \mathrm{~h} 30 \mathrm{~min}$ às $17 \mathrm{~h}$.

Os animais ficaram em baias no período das $12 \mathrm{~h}$ às $12 \mathrm{~h} 30 \mathrm{~min}$ e das $17 \mathrm{~h}$ até às 8h. As ovelhas pertencentes ao mesmo tratamento permaneceram em uma mesma baia, totalizando quatro áreas. Cada baia possuía água ad libitum e um cocho coletivo. Os cochos possuíam área linear de $0,40 \mathrm{~m} /$ animal para evitar disputa pelo alimento.

As ovelhas foram levadas do piquete para sua respectiva baia onde receberam
$50 \%$ do total concentrado do tratamento às $12 \mathrm{~h}$. Os animais que pertenciam ao tratamento que não recebeu concentrado também foram levados para a sua baia e disponibilizou-se sal mineralizado ad libitum. Às $12 \mathrm{~h} 30 \mathrm{~min}$ as ovelhas foram soltas no piquete.

$\mathrm{O}$ mesmo procedimento foi realizado às $17 \mathrm{~h}$, portanto, forneceu-se o restante do concentrado de acordo com o total de cada tratamento.

Os animais foram pesados no início do experimento (após a adaptação) e no final, ambos após jejum de sólidos por 16 horas, para determinação das variáveis ganhos em peso total e diário. Para ajuste do concentrado, pesou-se as ovelhas a cada vinte dias antes de serem liberadas para o piquete, às oito horas. Nos dias das pesagens para o ajuste, não houve manejo alimentar diferente da rotina; também nesta data, amostras da forragem e do concentrado foram coletadas para análises bromatológicas (Tabela 1). Para determinações de matéria seca, cinzas, extrato etéreo e proteína bruta, seguiu-se as metodologias conforme o proposto por Silva \& Queiroz (2002). Para a quantificação da fibra em detergente neutro (FDN), nitrogênio insolúvel em FDN, fibra em detergente ácido (FDA), nitrogênio insolúvel em FDA, celulose, hemicelulose e lignina, utilizou-se as metodologias proposta por Van Soest et al. (1991).

A conversão alimentar (eficácia da transformação da quantidade ingerida de concentrado por quilo de peso vivo ou quilo de carcaça produzida) foi calculada considerando-se o concentrado ingerido e o consumo estimado de matéria seca do pasto. Utilizou-se o peso vivo em jejum ou o peso da carcaça quente para suas estimativas, respectivamente. Calculouse também os custos referente à ingestão do concentrado em função do peso vivo ou do peso da carcaça e o 
mesmo procedimento para o volumoso. Os demais custos de produção não foram considerados. Multiplicou-se a conversão alimentar pela estimativa de consumo do volumoso para cada tratamento, somando-se. Para isso, utilizou-se os preços por quilo do ingrediente descritos a seguir: grão de sorgo ( $\mathrm{R} \$ 0,60)$, ureia $(\mathrm{R} \$ 1,28)$, farelo de soja ( $\mathrm{R} \$ 1,80)$, sal mineralizado ( $\mathrm{R}$. $1,50)$ e volumoso (R\$ 0,20). Portanto, o custo do concentrado foi de $\mathrm{R} \$ 0,69 / \mathrm{kg}$ de concentrado e o do pasto de $\mathrm{R} \$$ $0,20 / \mathrm{kg}$.

Tabela 1. Composição bromatológica (\%) do concentrado e da forrageira Panicum maximum, cv Massai

\begin{tabular}{lcc}
\hline Nutrientes & Forragem & Concentrado \\
\hline Matéria Seca & 27,52 & 89,89 \\
Cinzas & 7,55 & 14,13 \\
Proténa Bruta & 14,01 & 26,92 \\
Extrato Etéreo & 1,89 & 1,61 \\
Fibra em Detergente Neutro & 74,16 & 32,90 \\
NIDN* & 0,65 & 0,34 \\
Fibra em Detergente Ácido & 34,19 & 19,47 \\
NIDA* & 0,34 & 0,31 \\
Hemicelulose & 39,98 & 13,43 \\
Celulose & 23,68 & 6,64 \\
Lignina & 3,16 & 2,68 \\
Carboidratos Não-Fibrosos & 15,38 & 41,53 \\
Nutrientes Digestíveis Totais** & 58,61 & 68,57 \\
\hline *NIDN = nitrogênio insolúvel em detergente neutro; NIDA $=$ nitrogênio insolúvel em detergente ácido; \\
**Conforme Weiss (1993). &
\end{tabular}

Depois da fase experimental de campo, as ovelhas foram pesadas após jejum de sólidos de 16 horas, segundo proposto por Rosa et al. (2007), e abatidas. A ordem de abate seguiu por sorteio de um animal por tratamento para diminuir o efeito tempo de abate. Os animais foram insensibilizados com posterior secção das veias jugulares e as artérias carótidas para sangria. Após a esfola e evisceração, as carcaças foram pesadas para obtenção do peso de carcaça quente. Determinou-se o peso do corpo vazio deduzindo-se do peso vivo em jejum os pesos dos conteúdos gastrointestinal e da bexiga. As gorduras omental, mesentérica, perirrenal e cavitária foram separadas dos seus respectivos órgãos para obtenção do peso da gordura nas vísceras. Essa variável, além do peso absoluto, foi calculada em função do peso do corpo vazio. Após a esfola, mediu-se o $\mathrm{pH}$ da carcaça quente com o auxílio de peagâmetro no músculo Longissimus dorsi.

O rendimento da carcaça quente foi calculado por meio da relação dos pesos vivos em jejum e das carcaças quente. As carcaças foram mantidas em câmara de resfriamento a aproximadamente $1^{\circ} \mathrm{C}$ por 24 horas. Após o resfriamento, foram novamente pesadas e medidos os respectivos valores de $\mathrm{pH}$. O rendimento da carcaça fria foi calculado da mesma forma que o da carcaça quente. A quebra de peso por resfriamento foi calculada, em percentagem, por meio da diferença 
de peso das carcaças quente e fria. Nas carcaças resfriadas foram realizadas, com uso de fita métrica, as mensurações do comprimento externo e interno; larguras do anterior, garupa e tórax; perímetros da garupa, perna e tórax; profundidade de tórax; comprimento da perna, segundo Sañudo \& Sierra (1986). Para calcular os índices de compacidade da perna e da carcaça, dividiu-se os pesos da perna e da carcaça fria pelo comprimento interno da carcaça, respectivamente.

$\mathrm{Na}$ meia carcaça direita, realizou-se corte perpendicular entre a décima segunda e a décima terceira costelas para expor a seção transversal do músculo Longissimus dorsi. A área de olho de lombo foi determinada a partir do contorno da área dessa seção sobre papel vegetal. Posteriormente, calculouse a sua percentagem em função do peso do corpo vazio. Ainda na seção transversal do músculo Longissimus dorsi, identificou-se o ponto referente a $3 / 4$ do comprimento desta seção, no qual foi medida, com paquímetro digital, a espessura de gordura. Posteriormente, os músculos Longissimus dorsi foram retirados das carcaças e congelados a $20^{\circ} \mathrm{C}$ e encaminhados para o Laboratório de Análise de Alimentos da Universidade Estadual de Montes Claros, no campus de Janaúba. Nas carnes foram medidas as colorações do músculo e da gordura subcutânea, perda de água por cozimento e textura. Do músculo, foram retirados dois bifes, ambos com 2,54. Os bifes utilizados para as avaliações da cor da carne e da gordura ficaram expostos ao ambiente por 30 minutos antes da realização das avaliações, para exposição da mioglobina ao oxigênio. As determinações da cor da carne e gordura foram realizadas com um espectrofotômetro Hunter, modelo Miniscan EZ no sistema CIE. Avaliou- se a luminosidade $\left(\mathrm{L}^{*}\right)$, a intensidade da cor vermelha $\left(\mathrm{a}^{*}\right)$ e a intensidade da cor amarela $\left(b^{*}\right)$. A calibração do aparelho foi realizada antes da leitura das amostras com um padrão branco e outro preto. Para a determinação da perda de água por cozimento, descongelaram-se as seções de carne em refrigerador a $4^{\circ} \mathrm{C}$ durante 24 horas, até que alcançassem temperatura interna de 2 a $5^{\circ} \mathrm{C}$, quando foram pesadas e levadas a um grill elétrico. Quando a temperatura no ponto frio dos bifes alcançou $40^{\circ} \mathrm{C}$, foram virados e o outro lado foi grelhado até que atingisse $71^{\circ} \mathrm{C}$ (RAMOS \& GOMIDE, 2007). Após esse procedimento, as seções de carne foram esfriadas em temperatura ambiente e pesadas novamente, para que se pudesse determinar a perda de água por cozimento, a partir da diferença entre os dois bifes descongelados e cozidos. Em seguida, retiraram-se das seções de carne quatro amostras cilíndricas, com $1,27 \mathrm{~cm}$ de diâmetro, que foram utilizadas para realização das análises objetivas de textura (força de cisalhamento) e medidas com aparelho tipo Warner-Bratzler, conforme (RAMOS \& GOMIDE, 2007).

A análise estatística foi realizada utilizando-se o peso inicial das ovelhas como covariável. Este ajuste deu-se, quando significativo $(\mathrm{P}<0,0500)$, de forma linear. $\mathrm{O}$ delineamento foi inteiramente casualizado e os dados foram interpretados por meio de análises de variância e regressão $(\mathrm{P}<0,0500)$. Quando a análise de variância foi significativa $(\mathrm{P}<0,0500)$, testou-se os modelos lineares e quadráticos para escolha daquele que apresentasse melhor adequacidade para variáveis estudadas. Para esta escolha, além da significância, levou-se em consideração o modelo que apresenta-se o maior coeficiente de determinação. 
Rev. Bras. Saúde Prod. Anim., Salvador, v.15, n.1, p.206-220 jan./mar., 2014 http://www.rbspa.ufba.br ISSN 15199940

\section{RESULTADOS E DISCUSSÃO}

O consumo de matéria seca de concentrado (valor observado) foi de 0,$01 ; 0,31 ; 0,64$ e $1,00 \mathrm{~kg} / \mathrm{dia}$ e o de matéria seca do pasto (valor estimado) foi de 1,$03 ; 0,83 ; 0,53$ e $0,23 \mathrm{~kg} / \mathrm{dia}$, respectivamente para os tratamentos zero; 0,$7 ; 1,4$ e $2,1 \%$ do peso vivo de oferta de concentrado. No tratamento $2,1 \%$, notou-se que, apesar de não ter sobras da suplementação, o consumo deu-se de maneira mais lenta. A metade correspondente servida às $12 \mathrm{~h}$ não foi ingerida completamente neste momento, porém, a ingestão foi total a partir das $17 \mathrm{~h}$.

Os resultados referentes ao ganho em peso, características de carcaça e gordura nas vísceras estão apresentados na Tabela 2. O ganho em peso diário e, consequentemente, o ganho em peso total tiveram efeito quadrático negativo com a inclusão do concentrado (Figura 1); seus pontos de máximo valor foram encontrados com a ingestão de $1,49 \%$ de concentrado.

Tabela 2. Ganho em peso, características de carcaças e gorduras nas vísceras de ovelhas alimentadas com teores crescentes de concentrado em função do peso vivo

\begin{tabular}{lcccccc}
\hline \multirow{2}{*}{ Variável } & \multicolumn{4}{c}{ Teor de concentrado (\%) } & \multirow{2}{*}{$\begin{array}{c}\text { Equação } \\
\text { regressão }\end{array}$} & \multirow{2}{*}{ CV (\%) } \\
\cline { 2 - 5 } & zero & 0,7 & 1,4 & 2,1 & \\
\cline { 1 - 4 } Ganho em peso total (kg) & 4,88 & 10,17 & 10,67 & 10,52 & 1 & 28,28 \\
Ganho em peso diário (g) & 61,00 & 127,10 & 133,40 & 131,50 & 2 & 34,63 \\
Carcaça quente (kg) & 19,03 & 20,25 & 20,88 & 21,13 & $\mathrm{Y}=20,35$ & 16,43 \\
Carcaça quente (\%) & 42,40 & 42,56 & 39.83 & 41,45 & $\mathrm{Y}=41,53$ & 6,92 \\
Carcaça fria (kg) & 18,32 & 19,84 & 20,42 & 20,62 & $\mathrm{Y}=19,83$ & 16,37 \\
Carcaça fria (\%) & 40,79 & 41,74 & 38,91 & 40,46 & $\mathrm{Y}=40,46$ & 6,78 \\
Quebra resfriamento (\%) & 3,77 & 1,96 & 2,28 & 2,38 & $\mathrm{Y}=2,50$ & 37,36 \\
Gordura nas vísceras (\%) & 3,87 & 4,94 & 7,65 & 5,19 & 3 & 25,64 \\
Área olho de lombo (\%) & 0,46 & 0,41 & 0,41 & 0,36 & 4 & 9,53 \\
Gordura subcutânea (mm) & 1,24 & 1,79 & 2,70 & 1,62 & $\mathrm{Y}=1,84$ & 41,77 \\
\hline
\end{tabular}

$1,2,3,4(\mathrm{P}<0,0500)$, representação gráfica nas figuras subsequentes.
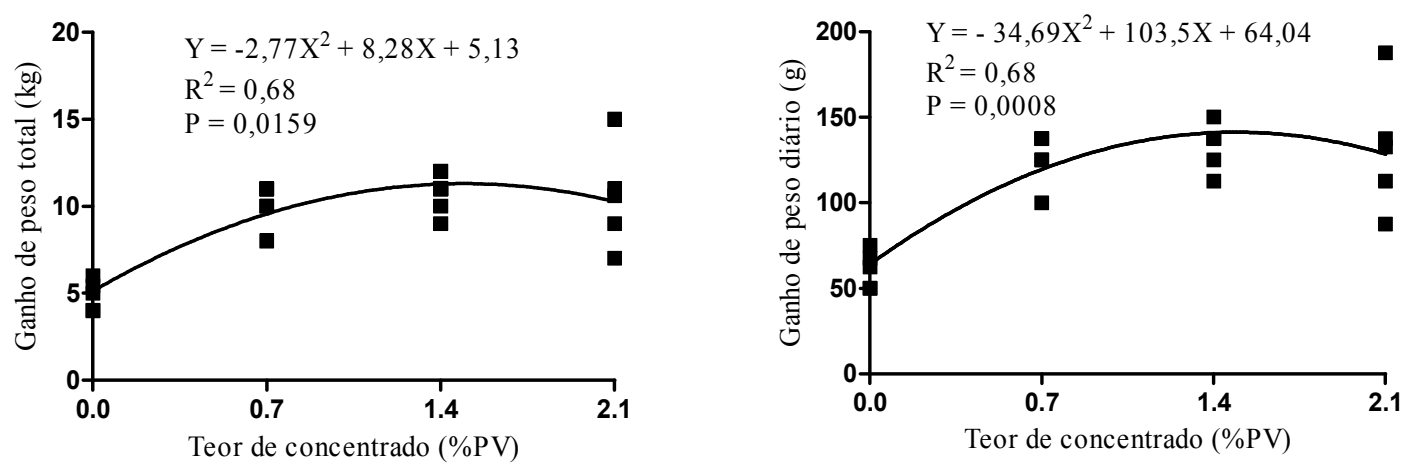

Figura 1. Ganhos de peso total e diário de ovelhas alimentadas com teores crescentes de concentrado em função do peso vivo 
A partir dos valores do consumo de matéria seca do concentrado e do volumoso (valor estimado) e com base na composição nutricional desses alimentos, percebe-se um incremento no aporte de nutrientes na medida em que se aumenta o teor de concentrado oferecido aos animais. Apesar desta constatação, os resultados de ganho em peso dos animais não seguiram uma tendência linear crescente. Em suas considerações sobre a nova sistemática de avaliação de respostas produtivas ao suprimento variável de nutrientes, Lana et al. (2005) concluíram que com o aumento do fornecimento de nutrientes, há decréscimo crescente na resposta produtiva dos bovinos, até atingir um limite em que a resposta deixa de ser positiva, causando inibição por toxidez.

Os pesos absolutos e relativos das carcaças quente e fria não mudaram quando a suplementação foi fornecida; a quebra de peso durante o resfriamento também não foi alterada.

$\mathrm{O}$ peso relativo da gordura nas vísceras teve efeito quadrático (Figura 2), seu ponto de máximo valor foi encontrado quando a suplementação foi de $1,33 \%$ do $\mathrm{PV}$. A gordura de cobertura não mudou e a área de olho de lombo diminuiu linearmente com o fornecimento crescente da suplementação (Figura 3).

Os comprimentos externo e interno da carcaça; as larguras do anterior e da garupa; o perímetro da garupa; profundidade do tórax; comprimento e perímetro da perna; compacidades da carcaça e perna, não mudaram suas medidas com a inclusão de concentrado na dieta (Tabela 3 ). Já as medidas do tórax das ovelhas (Tabela 3 e Figura 4), largura e perímetro, aumentaram linearmente com $o$ acréscimo da suplementação.

Neste experimento, o desenvolvimento corporal das ovelhas, até seu ponto de máximo valor, deu-se no sentido da deposição de gordura nas vísceras, encontrado também por Maior Júnior et al. (2008) em borregos sem raça definida. O aumento das medidas do tórax, única variável morfométrica alterada, aconteceu em pequenas proporções; o que acarretou na semelhança do peso e morfometria das carcaças nos diferentes tratamentos.

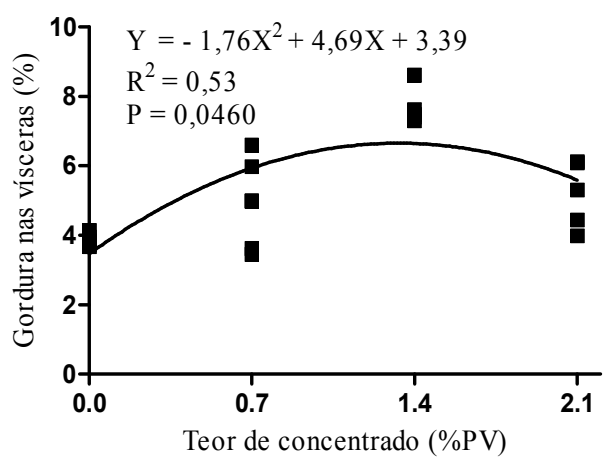

Figura 2. Percentagem de gordura nas vísceras de ovelhas alimentadas com teores crescentes de concentrado em função do peso vivo

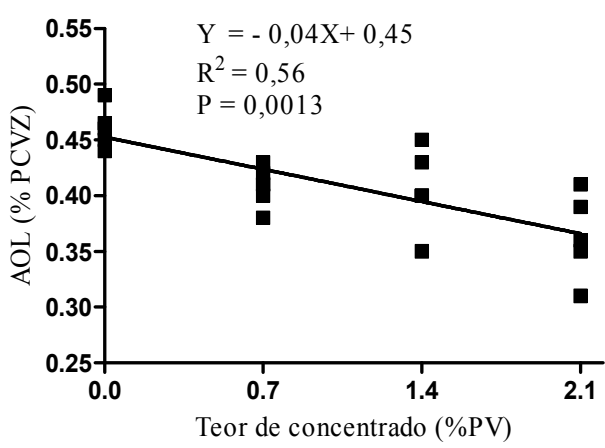

Figura 3. Área de olho de lombo (\%PCVZ) de ovelhas alimentadas com teores crescentes de concentrado em função do peso vivo 
Rev. Bras. Saúde Prod. Anim., Salvador, v.15, n.1, p.206-220 jan./mar., 2014 http://www.rbspa.ufba.br ISSN 15199940

Tabela 3. Morfometria na carcaça $(\mathrm{cm})$ das ovelhas alimentadas com teores crescentes de concentrado em função do peso vivo

\begin{tabular}{lcccccc}
\hline \multirow{2}{*}{ Variável } & \multicolumn{4}{c}{ Teor de concentrado } & Equação & \multirow{2}{*}{ CV(\%) } \\
\cline { 2 - 5 } & zero & 0,7 & 1,4 & 2,1 & regressão & \\
\hline Comprimento externo & 67,25 & 69,00 & 63,00 & 67,00 & $\mathrm{Y}=66,51$ & 9,08 \\
Comprimento interno & 76,80 & 72,75 & 77,47 & 78,54 & $\mathrm{Y}=76,27$ & 5,45 \\
Largura do anterior & 15,97 & 16,75 & 16,58 & 16,88 & $\mathrm{Y}=16,56$ & 8,16 \\
Largura da garupa & 21,83 & 22,00 & 21,74 & 22,48 & $\mathrm{Y}=22,00$ & 6,86 \\
Largura do tórax & 14,93 & 15,63 & 16,02 & 16,64 & 1 & 4,63 \\
Perímetro da garupa & 66,84 & 66,13 & 65,54 & 69,97 & $\mathrm{Y}=67,00$ & 6,96 \\
Profundidade de tórax & 29,75 & 31,75 & 30,65 & 30,86 & $\mathrm{Y}=30,79$ & 7,23 \\
Perímetro da perna & 44,45 & 42,00 & 40,14 & 46,53 & $\mathrm{Y}=43,28$ & 7,77 \\
Perímetro do tórax & 68,84 & 68,75 & 73,92 & 75,21 & 2 & 7,99 \\
Comprimento da perna & 44,05 & 41,75 & 42,93 & 43,69 & $\mathrm{Y}=43,04$ & 5,49 \\
Comp. carcaça $(\mathrm{kg} / \mathrm{cm})^{3}$ & 0,24 & 0,27 & 0,26 & 0,26 & $\mathrm{Y}=0,26$ & 13,19 \\
Comp. perna $(\mathrm{kg} / \mathrm{cm})^{4}$ & 0,50 & 0,53 & 0,51 & 0,51 & $\mathrm{Y}=0,51$ & 6,00 \\
\hline 1,2 $(\mathrm{P}<0,0500)$, Representação & gráfica & nas & figuras & subsequentes; ${ }^{3}$ Peso & da carcaça dividido pelo \\
comprimento interno da carcaça; ${ }^{4}$ Peso da perna dividida pelo seu comprimento. &
\end{tabular}
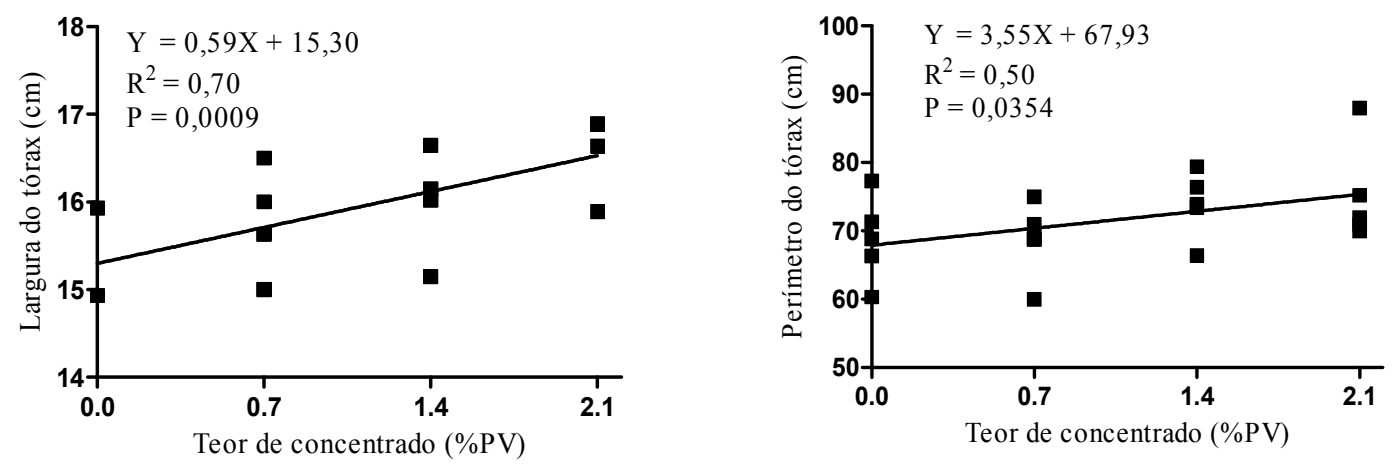

Figura 4. Largura e perímetro do tórax de carcaças de ovelhas alimentadas com teores crescentes de concentrado em função do peso vivo

Os animais, mesmo aqueles que tiveram maior consumo de nutrientes, mostraram-se ineficazes para $o$ desenvolvimento de tecidos muscular na carcaça nesta idade fisiológica. A área de olho de lombo reforça esta hipótese, já que seus valores diminuíram linearmente. Esta averiguação deve-se a possível manutenção do peso absoluto do tecido muscular nas carcaças, diluído em um maior ganho em peso corporal para ovelhas que ingeriram mais concentrado. Pelegrini et al. (2008) trabalhando com carcaça de ovelhas de descarte das raças Ideal e Texel terminadas em dois sistemas de alimentação (confinamento ou em pastagem cultivada sem adição de concentrado), observaram que as ovelhas terminadas em confinamento atingiram em menor tempo a condição de abate, porém, os ganhos no confinamento não refletiram significativamente nos pesos absolutos e relativos de carcaças quente 
e fria, resultados que corroboram com este ensaio.

O fato de este trabalho utilizar ovelhas que não eram especializadas para produção de carne, pode explicar o resultado da ineficácia no desenvolvimento da carcaça, somado também a idade dos animais e ao sexo. Pinheiro et al. (2009) relataram que ovelhas Santa Inês em estágio fisiológico que requeriam menos nutrientes, quando disponibilizados, aumentaram gordura interna. Este acréscimo de gordura visceral poderá trazer prejuízo ao produtor devido ao menor valor econômico deste produto.

A conversão alimentar das ovelhas e o respectivo custo de produção da ingestão da suplementação proteica encontram-se na Tabela 4. A conversão alimentar, quilo de alimento ingerido por quilo de peso vivo produzido, apresentou efeito quadrático positivo; resultado semelhante ocorreu para esta variável em função do quilo de carcaça produzida (Figura 5). Para as duas simulações, o ponto de mínimo valor foi encontrado com a ingestão do concentrado de $1,42 \%$ do PV.

Tabela 4. Conversão alimentar e custos de produção de ovelhas alimentadas com teores crescentes de concentrado em função do peso vivo

\begin{tabular}{|c|c|c|c|c|c|c|}
\hline \multirow{2}{*}{ Variável } & \multicolumn{4}{|c|}{ Teor de concentrado $(\%)$} & \multirow{2}{*}{$\begin{array}{c}\text { Equação } \\
\text { regressão }\end{array}$} & \multirow{2}{*}{$\mathrm{CV}(\%)$} \\
\hline & zero & 0,7 & 1,4 & 2,1 & & \\
\hline C.A.* (kg dieta./kg PV)_ & 17,58 & 10,64 & 8,34 & 10,37 & 1 & 32,03 \\
\hline Custo (R\$/kg PV) & 3,87 & 3,55 & 3,90 & 6,95 & 2 & 21,05 \\
\hline C.A. ${ }^{* *}$ (kg dieta/ kg Car.) & 44,00 & 25,25 & 21,01 & 25,22 & 3 & 32,00 \\
\hline Custo (R $\$ / k g$ Car.) & 8,74 & 8,36 & 9,82 & 17,02 & 4 & 21,07 \\
\hline
\end{tabular}

*Conversão do concentrado e volumoso ingeridos por kg de peso vivo produzido.

**Conversão do concentrado e volumoso ingeridos por $\mathrm{kg}$ de peso de carcaça produzido.

1, 2, 3, $4(\mathrm{P}<0,0500)$, representação gráfica nas figuras subsequentes.
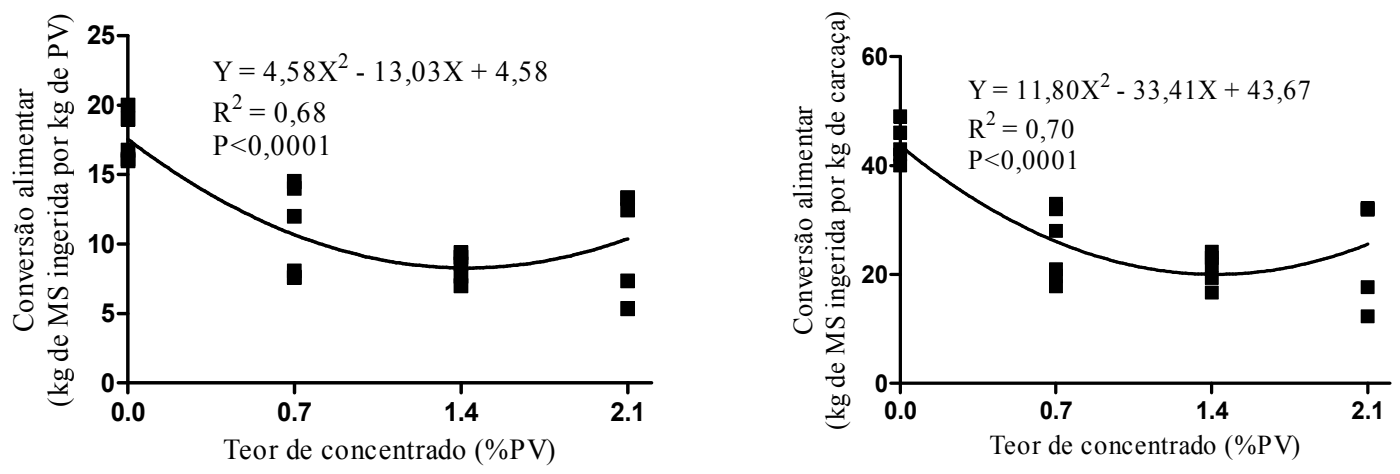

Figura 5. Conversão alimentar ( $\mathrm{kg}$ de concentrado e volumoso por $\mathrm{kg}$ de $\mathrm{PV}$ ou por $\mathrm{kg}$ de carcaça) de ovelhas alimentadas com teores crescentes de concentrado em função do peso vivo 
O custo de produção por quilo de peso vivo ou por quilo da carcaça (Figura 6) apresentou função quadrática positiva. $O$ ponto de ingestão de concentrado que apresentou menor custo foi de 0,68 ou $0,62 \%$ do PV por quilo da ovelha viva ou de sua carcaça, respectivamente. A diferença do custo de produção do quilo da carcaça das ovelhas que não

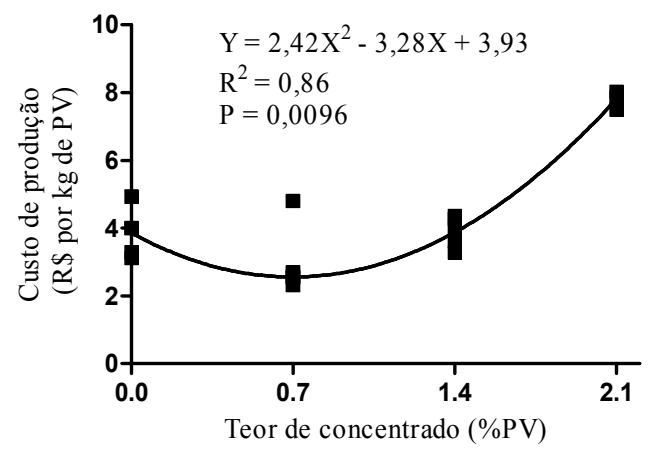

ingeriam concentrado $e$ as que consumiram neste ponto de mínimo valor foi de $32 \%$.

A conversão alimentar foi melhor no momento em que o ganho em peso foi mais alto, contudo, o custo benefício ficou abaixo deste ponto devido a pressão dos valores dos ingredientes da suplementação.

Figura 6. Custo de produção do peso vivo ou da carcaça de ovelhas alimentadas com teores crescentes de concentrado em função do peso vivo

As variáveis relacionadas com a qualidade da carne de ovelhas encontram-se na Tabela 5. Ovelhas que consumiram $0,61 \%$ do PV de concentrado apresentaram maiores valores de $\mathrm{pH}$ final, os valores decresceram depois deste ponto (Figura 7), já o pH inicial não mudou. As variáveis ligadas a cor do músculo, cromaticidades $a^{*}$ e b* e luminosidade, também não diferiram em relação aos tratamentos.

A cor da gordura apresentou alterações em função dos tratamentos; ovelhas que ingeriram $0,64 \%$ de concentrado tiveram menores valores de luminosidade, sendo que a equação encontrada foi quadrática positiva (Figura 8). Para as demais variáveis de cor da gordura, cromaticidades $\mathrm{a}^{*} \mathrm{e} \mathrm{b}^{*}$,

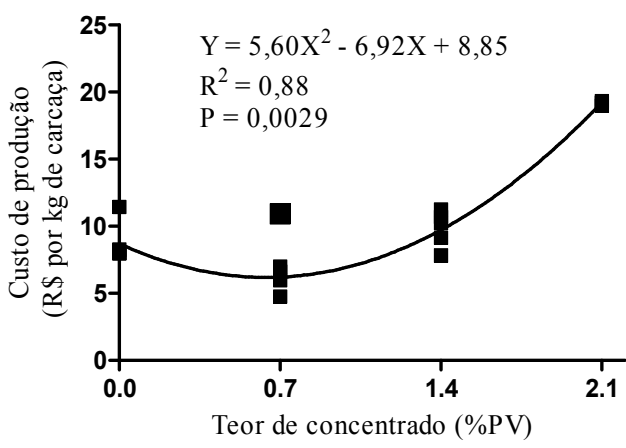

não houve mudanças com a inclusão dos teores de concentrado.

A ingestão de concentrado diminuiu as perdas ocorridas durante o cozimento (Figura 9); a variável apresentou função quadrática positiva e o menor valor de perda foi encontrado quando os animais ingeriram $2,0 \%$ de concentrado em relação ao PV. Não houve variação na textura da carne, representada neste trabalho pela força de cisalhamento, quando se acrescentou concentrado em maiores proporções na dieta.

Quando se discute a qualidade da carne das ovelhas, alguns resultados privilegiaram ovelhas que consumiram mais concentrado.

Respeitando as condições de bem-estar ante mortem, $\mathrm{o} \mathrm{pH}$, após o abate do animal, reduz de aproximadamente 7 para 5,5 (BONAGURIO et al., 2003). 
Rev. Bras. Saúde Prod. Anim., Salvador, v.15, n.1, p.206-220 jan./mar., 2014 http://www.rbspa.ufba.br ISSN 15199940

Tabela 5. Variáveis de qualidade da carne das ovelhas de descarte alimentadas com níveis crescentes de concentrado em função do peso vivo

\begin{tabular}{|c|c|c|c|c|c|c|}
\hline \multirow{2}{*}{ Variável } & \multicolumn{4}{|c|}{ Nível de concentrado (\%) } & \multirow{2}{*}{$\begin{array}{l}\text { Equação } \\
\text { regressão }\end{array}$} & \multirow{2}{*}{$\mathrm{CV}(\%)$} \\
\hline & zero & 0,7 & 1,4 & 2,1 & & \\
\hline $\mathrm{pH}$ inicial & 6,50 & 6,64 & 6,64 & 6,35 & $\mathrm{Y}=6,54$ & 4,12 \\
\hline pH final & 5,69 & 5,72 & 5,66 & 5,51 & 1 & 1,83 \\
\hline Luminosidade do músculo & 30,15 & 27,75 & 32,07 & 30,45 & $Y=30,09$ & 8,21 \\
\hline Cromaticidade a*do músculo & 9,67 & 10,49 & 10,26 & 9,84 & $\mathrm{Y}=10,09$ & 12,90 \\
\hline Cromaticidade $b^{*}$ do músculo & 12,07 & 11,68 & 11,65 & 10,57 & $\mathrm{Y}=11,51$ & 11,21 \\
\hline Luminosidade da gordura & 49,07 & 48,31 & 49,35 & 56,46 & 2 & 11,79 \\
\hline Cromaticidade $\mathrm{a} *$ da gordura & 3,39 & 2,93 & 4,41 & 3,10 & $Y=3,46$ & 32,00 \\
\hline Cromaticidade $b^{*}$ da gordura & 10,07 & 11,09 & 12,24 & 11,66 & $\mathrm{Y}=11,30$ & 16,62 \\
\hline Perdas durante o cozimento & 19,37 & 18,96 & 13,26 & 14,65 & 3 & 22,14 \\
\hline Forca cisalhamento $\left(\mathrm{kgf} / \mathrm{cm}^{2}\right)$ & 4,38 & 5,01 & 3,93 & 4,83 & $\mathrm{Y}=4.53$ & 20,98 \\
\hline
\end{tabular}

$1,2,3(\mathrm{P}<0,0500)$, representação gráfica nas figuras subsequentes.

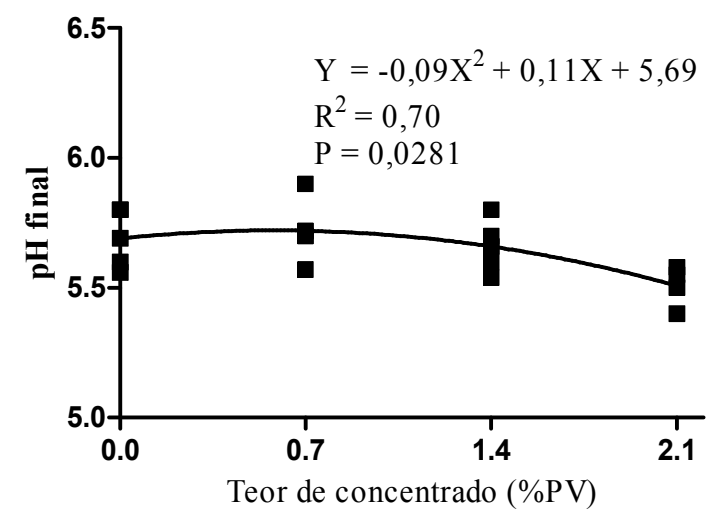

Figura 7. $\mathrm{pH}$ final de carcaças de ovelhas alimentadas com teores crescentes de concentrado em função do peso vivo

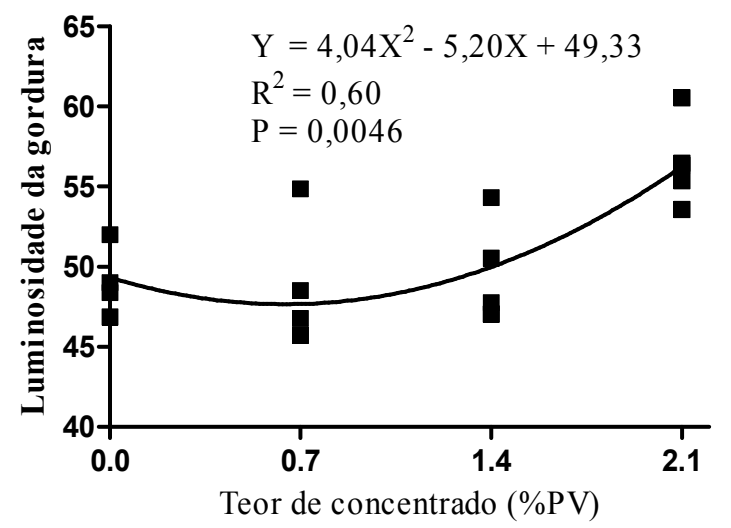

Figura 8. Luminosidade da gordura da carne de ovelhas alimentadas com teores crescentes de concentrado em função do peso vivo 


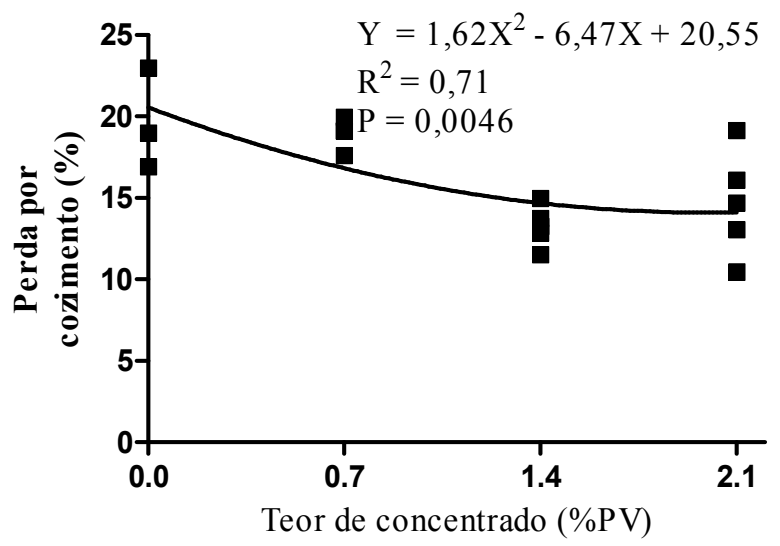

Figura 9. Perda por cozimento da carne de ovelhas alimentadas com teores crescentes de concentrado em função do peso vivo

Valores mais baixos de $\mathrm{pH}$ final podem proporcionar carnes mais macias $\mathrm{e}$ maior vida-de-prateleira, devido a maior acidez e, consequente, menor crescimento de microrganismos (LAWRIE, 2005).

A hipótese de que a carne pode ficar mais macia (testada aqui pela força de cisalhamento) em $\mathrm{pH}$ final mais baixo não foi encontrada neste experimento, contudo, a vida-de-prateleira pode aumentar nas carnes das ovelhas que ingeriram mais concentrado, devido ao resultado já apresentado. A favor dos demais tratamentos, Prates (2000) afirmou que o $\mathrm{pH}$ final para a carne ovina deve situar-se de 5,5 a 5,8 de 12 a 24 horas decorrido o abate; todos os valores deste ensaio encontram-se nesse intervalo. Os valores médios encontrados também em todos os grupos estão abaixo de $11 \mathrm{kgf}$, considerados por Souza et al. (2004) como limite superior para considerar a carne como macia.

$\mathrm{pH}$ final mais baixo também está relacionado com menores capacidades de retenção de água, devido a maior proximidade com o ponto isoelétrico das proteínas (HUFF-LONERGAN \& LONERGAN, 2005). Esta característica, quando presente, pode diminuir rendimentos de produtos no momento do preparo para o consumo humano (descongelamento, cozimento) e/ou durante as etapas antes do rigor mortis. Porém, como já dito, o abaixamento do $\mathrm{pH}$ é importante para a qualidade da carne.

Neste trabalho, observou-se o contrário em relação à associação do $\mathrm{pH}$ e perdas durante o cozimento, provavelmente devido a uma maior deposição de gorduras intermuscular e/ou intramuscular nas carnes, mesmo não possuindo diferenças na gordura de cobertura. Para Ferguson e Warner (2008), algumas variações ocorrem independente do $\mathrm{pH}$ final e citaram a capacidade de retenção de água como uma das medidas a serem acrescentadas para avaliar a qualidade das carnes.

Estimando-se as perdas por cozimento para uma ingestão de $0,62 \%$ do PV de concentrado, ponto de melhor custo para produção do quilo de carcaça, e para $2,0 \%$, ponto de maior rendimento da carne durante o cozimento, encontrase diferença de $21,79 \%$ a favor da última. Portanto, cria-se um paradoxo do que é mais rentável para o produtor e o que é melhor para o proprietário de restaurante. Além das questões de 
rendimento, Trout (1988) indicou que métodos que utilizam tratamento térmico podem estar relacionados com a suculência da carne e que maiores perdas durante o cozimento podem piorar esse atributo.

O grão de sorgo tem baixa concentração de carotenoides (MOURA et al., 2009) e a cor da gordura de ovinos já é naturalmente mais clara quando comparada a de bovinos devido à baixa concentração dessa substância (YANG et al., 1992), o que deturpa o resultado, já que ovelhas que tiveram ingestão de dieta com maior relação concentrado volumoso apresentaram gordura subcutânea no Longissimus dorsi com menor brilho. Este foi a única variável que mudou na coloração da carne (gordura subcutânea e tecido muscular). Variações de 30,03 a 49,47 para luminosidade ( $L^{*}$ ), de 8,24 a 23,53 para intensidade de vermelho (a*) e de 3,38 a 11,10 para intensidade de amarelo $\left(b^{*}\right)$ são citadas em carnes de ovinos (somente tecido muscular) (SAÑUDO et al., 2000). Nota-se que todos os tratamentos apresentaram, quando comparados com a referência acima, carnes com valores de $L^{*}$ e a* próximos do limite inferior, ou seja, com menores brilho $\left(\mathrm{L}^{*}\right)$ e intensidade de vermelho ( $\left.a^{*}\right)$ e maior intensidade de amarelo $\left(b^{*}\right)$, possivelmente por serem de fêmeas mais velhas. Contudo, Pinheiro et al. (2010) encontraram melhor coloração nas carnes de animais desta mesma categoria.

A suplementação concentrada $(90,64 \%$ de panícula de sorgo triturada, $2 \%$ de ureia, $4,36 \%$ de farelo de soja e $3 \%$ de sal mineralizado comercial) não mudou as características físicas das carcaças das ovelhas. Ovelhas que ingeriram $1,49 \%$ do seu peso vivo em concentrado apresentaram maior ganho em peso corporal, reflexo da maior deposição de gordura nas vísceras.
Ovelhas que ingeriram $0,62 \%$ do concentrado do seu peso vivo apresentaram melhor custo benefício para produção das carcaças.

A suplementação em seu teor máximo $(2,1 \%)$ apresentou melhor $\mathrm{pH}$ final das carnes.

Carnes de ovelhas que ingeriram 2,0\% da suplementação concentrada perderam menos peso durante o cozimento.

Para quaisquer teores de ingestão de concentrado ou para animais que se alimentaram somente de pasto (Panicum maximum), as carnes foram consideradas macias e coloração no limite inferior da faixa normal da espécie.

\section{AGRADECIMENTOS}

A família proprietária da Fazenda da Pedra, Agreste, Januária, MG. Ao CNPq, CAPES e FAPEMIG por concederem bolsas de estudo.

\section{REFERÊNCIAS}

ALVES, D.D.; ARAÚJO, L.M.; MONTEIRO, H.C.F.; LEONEL, F.P.; SILVA, F.V.; SIMÕES, D.A.; GONÇALVES, W.C.; BRANT, L.M.S. Características de carcaça, componentes não-carcaça e morfometria em ovinos submetidos a diferentes estratégias de suplementação. Semina: Ciências

Agrárias, v.34, n.6, p.3093-3104, 2013.

BONAGURIO, S.; PÉREZ, J.R.O.; GARCIA, I.F.F; BRESSAN, M.C.; LEMOS, A.L.S.C. Qualidade da carne de cordeiros Santa Inês puros e mestiços com Texel abatidos com diferentes pesos. Revista Brasileira de Zootecnia, v.32, n.6, p.1981-1991, 2003. 
BUTTERFIELD, R.M. News concepts of sheep growth. Sydney: Sydney University, 1988. 168p.

DANTAS, A.F.; PEREIRA FILHO, J.M.; SILVA, A.M.A.; SANTOS, E.M.; SOUSA, B.B.; CÉZAR, M.F.

Características da carcaça de ovinos

Santa Inês terminados em pastejo e submetidos a diferentes níveis de suplementação. Ciência Agrotécnica, v.32, n.4, p.1280-1286, 2008.

FERGUSON, D.M.; WARNER, R.D. Have we underestimated the impact of pre-slaughter stress on meat quality in ruminants? Review. Meat Science, v.80, p.12-19, 2008.

HUFF-LONERGAN, E.; LONERGAN, S.M. Mechanisms of water-holding capacity of meat: The role of postmortem biochemical and structural changes.

Review. Meat Science, v.71, p.194-204, 2005.

LANA, R.P.; GOES, R.H.T.B.; MOREIRA, L.M.; MÂNCIO, A.B.; FONSECA, D.M.; TEDESCHI, L.O. Application of Lineweaver-Burk data transformation to explain animal and plant performance as a function of nutrient supply. Livestock Production

Science, v.98, n.3, p.219-224, 2005.

LAWRIE, R.A. Ciência da Carne. 6.ed. Porto Alegre: Artmed, 2005. 384 p.

MAIOR JÚNIOR, R.J.S.; CARVALHO, F.F.R.; BATISTA, A.M.V.;

VASCONCELOS, R.M.J.; SILVA, R.C.B. FIGUEIREDO, M.A.S.

Rendimento e características dos componentes não-carcaça de ovinos alimentados com rações baseadas em cana -de-açúcar e uréia. Revista Brasileira de Saúde e Produção Animal [online], v.9, n.3, p.507-515, 2008.
MOURA, A.M.A.; TAKATA, F.N.; NASCIMENTO, G.R.; SILVA, A.F.; MELO, T.V.; CECON, P.R.

Pigmentantes naturais em rações à base de sorgo para codornas japonesas em postura. Revista Brasileira de Zootecnia, v.40, n11, p.2443-2449, 2011.

MURTA, R.M.; CHAVES, M.A.; SILVA, F.V.; BUTERI, C.B.; FERNANDES, O.W.B.; SANTOS, L.X. Ganho em peso e características da carcaça de ovinos confinados alimentados com bagaço de cana hidrolisado com óxido de cálcio. Ciência Animal Brasileira, v.10, n.2, p.438-445, 2009.

PELEGRINI, L.F.; PIRES, C.C; GALVANI, D.B; BOLZAN, A.M.; SILVA, G.C.F.S. Características de carcaça de ovelhas de descarte das raças Ideal e Texel terminadas em dois sistemas de alimentação. Revista Brasileira de Zootecnia, v.37, n.11, p.2024-2030, 2008.

PINHEIRO, R.S.B.; JORGE, A.M.; SOUZA, H.B.A. Características da carcaça e dos não-componentes da carcaça de ovelhas de descarte abatidas em diferentes estágios fisiológicos.

Revista Brasileira de Zootecnia, v.38, n. 7, p.1322-1328, 2009.

PINHEIRO, R.S.B.; JORGE, A.M.; SOUZA, H.B.A.; BOIAGO, M.M. Coloração da gordura e qualidade da carne de ovelhas de descarte abatidas em distintos estágios fisiológicos.

Arquivo Brasileiro de Medicina Veterinária e Zootecnia, v.62, n.2, p.468-474, 2010.

PRATES, J.A.M. Maturação da carne dos mamíferos: 1. Caracterização geral e modificações físicas. Revista

Portuguesa de Ciências Veterinárias, v.95, n.533, p.34-41, 2000. 
RAMOS, E.M.; GOMIDE, L.A.M. Avaliação da qualidade de carnes: fundamentos e metodologia. Viçosa: Universidade Federal de Viçosa, 2007. p.69-72.

ROSA, G.T.; SIQUEIRA, E.R.; GALLO, S.B.; MORAES, S.S.S. Influência da suplementação no préparto e da idade de desmama sobre o desempenho de cordeiros terminados em confinamento. Revista Brasileira de Zootecnia, v.36, n.4, p.953-959, 2007.

SAÑUDO, C.; SIERRA, I. Calidad de la canal en la especie ovina. Revista Ovis, v.1, p.127-53, 1986.

SAÑUDO, C; ENSER M.E.; CAMPO M.M.; NUTE G.R.; MARÍA G.; SIERRA I.E.; WOOD J.D. Fatty acid composition and sensory characteristics of lamb carcasses from Britain and Spain. Meat Science, v.54, n.4, p.339346, 2000.

SILVA, D.J.; QUEIROZ, A.C. Análises de alimentos: métodos químicos e biológicos. 3.ed. Viçosa, MG: UFV, 2002. 235p.

TEDESCHI, L.O.; CANNAS, A.; FOX, D.G. A nutrition mathematical model to account for dietary supply and requirements of energy and nutrients for domesticated small ruminants: the development and evaluation of the Small Ruminant Nutrition System.

Revista Brasileira de Zootecnia, v.37, p.179-190, 2008.

TEDESCHI, L.O.; CANNAS, A.; FOX, D.G. A nutrition mathematical model to account for dietary supply and requirements of energy and other nutrients for domesticated small ruminants: The development and evaluation of the Small Ruminant
Nutrition System. Small Ruminant

Research, v.89, p.174-184, 2010.

TROUT, G.R. Techniques for

Measuring Water-Binding Capacity in Muscle Foods. A Review of Methodology. Meat Science, v.23, 235252, 1988.

VAN SOEST, P.J.; ROBERTSON, J.B.; LEWIS, B.A. Methods for dietary fiber, neutral detergent fiber and nonstarch polysaccharides in relation to animal nutrition. Journal of Dairy Science, v.74, p.3583-3597, 1991.

WEISS, W.P. Predicting energy values of feeds. In: Symposium: prevailing concepts in energy utilization by ruminants. Journal of Dairy Science, v.76, p.1802-1811, 1993.

YANG,A.; LARSEN, T.W.; TUME, R.K. Carotenoid and retinol concentrations in serum, adipose tissue and liver and carotenoid transport in sheep, goats and cattle. Australian Journal of Agricultural Research, v.43, n.8, p.1809-1817, 1992.

SOUZA, X.R.; BRESSAN, M.C.; PÉREZ, J.R.O.; FARIA, P.B.; VIEIRA, J.O; KABEYA, D.M. Efeitos do grupo genético, sexo e peso ao abate sobre as Propriedades físico-químicas da carne de Cordeiros em crescimento.

Tecnologia de Alimentos, v.24, n.4, p.543-549, 2004.

Data de recebimento: 04/11/2013

Data de aprovação: 26/03/2014 